i-DUST 2010, $01001(2011)$

DOI: 10.1051 idust/201101001

(C) Owned by the authors, published by EDP Sciences, 2011

\title{
Hydrodynamic organisation of the flows in the unsaturated zone of the Fontaine de Vaucluse karst system. First results
}

\author{
A. Perineau, C. Danquigny, C. Emblanch, E. Pozzo di Borgo, D. Boyer, \\ and J. Poupeney
}

\begin{abstract}
Karst systems contain important groundwater resources. Due to their complexity, they are generally under exploited. Particularly, the hydrodynamic functioning of the unsaturated zone is badly understood even if its important role is admitted Today, the hydrogeologists are agreeing with the important function(s) of the unsaturated zone in karst systems, but today this role(s) is badly characterized. As they are very complex systems, karst aquifers are generally under exploited. It is necessary to progress in the understanding of the functioning of the karst systems and particulary in the functioning of the unsaturated zone in order to develop the corresponding management tools. The study of the unsaturated zone of a karst system needs some access to this part of the aquifer. Speleological access is not sufficient because the major part of the water flows in not humanly enterable drains. The Low-Noise Underground Laboratory of RustrelPays d'Apt (LSBB) is an artificial gallery digged in the unsaturated zone of the Fontaine de Vaucluse karst aquifer catchment area. It intersects arbitrarily the fault networks in depth and then the potential areas of flows through the unsaturated zone. From 2002 to 2009, 61 points where water regularly flows have been identified. For each, flow rate has been periodically monitored. This first global study of the acquired data shows a good relation between flows and geological structures. An organization of flows with depth and geology is also underlined. With increasing depth, flows seem to concentrate from numerous faults networks to a little number of high discontinuities.
\end{abstract}

\section{INTRODUCTION}

Karst systems contain important groundwater resources for the global supply in drinking water [1]. Karst formations cover a significant part of the territory: 33\% in France, 30 to $70 \%$ around the Mediterranean Sea [2] and $10 \%$ of the Earth surface. As they are very complex systems, karst aquifers are generally under exploited; their resources could potentially be used in the future to meet a growing demand. It is necessary to progress in the understanding of the functioning of the karst systems in order to develop the corresponding management tools.

From a hydrogeological point of view, during the last decades, the studies concerning the karst systems led the hydrogeologists to propose numerous conceptual models of the karst systems based on the outlet response [3-5] using hydrodynamics, hydrochemical and/or isotopic studies. Even if karst systems exhibit highly heterogeneous drainage due to uneven permeability development through carbonate dissolution, hydrogeologists accord them to subdivide the karst systems into 4 main parts [6]: (1) The soil and non karst terrain, (2) The epikarst [1, 7], (3) The unsaturated zone [7-9], (4) The saturated zone. All these sub-systems don't have systematically the same function and do not systematically exist. While these conceptual model presents the advantage to be relatively generic, it remains mostly qualitative $[10,11]$. Thus characterization of the karst systems and improvement of the definition of a generic conceptual model remain necessary [9].

Many models are available for rainfall-discharge relationships in karst systems, such as reservoirbased models. However, they poorly rely on the physical properties of functioning of karst systems.

This is an Open Access article distributed under the terms of the Creative Commons Attribution-Noncommercial License 3.0, which permits unrestricted use, distribution, and reproduction in any noncommercial medium, provided the original work is properly cited. 
i-DUST 2010

The mode of recharge and transfer through the vadose zone (soil, epikarst and infiltration zone) is a key variable in the development of rainfall-discharge model. The degree of karstification influences the mode of infiltration that is also controlled by the connectivity of the flowpath network within the vadose zone. This connectivity controls both the amount of water stored in the vadose zone and the water flowing towards the springs and the saturated zone. It is thus necessary to quantify this phenomenon with respect to the amount of precipitation by a function distinct from infiltration.

Today, hydrogeologists are agreeing with the important role(s) of the unsaturated zone in the functioning of the karst systems. But today this role(s) is badly characterized [12]. It is essential to understand the functioning of the unsaturated zone and its impact on the flows from the surface to the saturated zone. There are few studies about the unsaturated zone, probably because this part of the aquifer is often inaccessible. And speleological access is not sufficient because the major part of the water flows in not humanly enterable drains [3].

However, in the catchment area of the Fontaine de Vaucluse, the Low Noise Underground Laboratory of Rustrel Pays d'Apt (LSBB) is an artificial gallery digged in the unsaturated zone of the karst system. Moreover, it cuts arbitrarily the karstic network, i.e. areas with variable fracturing density and at different depths. It permits to observe different kinds of flows.

The main objective of this study is to underline some relations between the geology, the depth and the kind of flow in the unsaturated zone. It is a step in the definition of the conceptual model of the unsaturated zone of the karst systems.

\section{STUDIED AREA}

The Low Noise Underground Laboratory of Rustrel Pays d'Apt (LSBB) is a $3.8 \mathrm{~km}$ long artificial underground gallery in the Fontaine de Vaucluse catchment area. In the past, the LSBB was part of the French nuclear dissuasive force. It was indeed the arrangement area of ballistic and strategic groundto-ground missiles (http://lsbb.oca.eu/). Actually, it is an interdisciplinary research laboratory which offers a unique access to the numerous flows which pass through the part of the karst system where it is drilled.

\subsection{The Fontaine de Vaucluse catchment area}

The Fontaine de Vaucluse is situated near Avignon (at about $30 \mathrm{~km}$ ) and is one of the biggest karst spring in the world with an average outlet discharge of $19 \mathrm{~m}^{3} / \mathrm{s}$ from 1970 to 2006 [14]. The limestone catchment area (fig. 1) is about $1.230 \mathrm{~km}^{2}$ (www.hydro.eaufrance.fr/). This aquifer is located in the lower Cretaceous and the thickness of the limestone series is $1500 \mathrm{~m}[15,16]$, from Necomanian marls to upper Aptian marls. From a geological point of view, the system is composed of a monoclinal, dipping towards south-west, which is affected by NW-SE and NE-SW faults (fig. 1). The Fontaine de Vaucluse is the main spring of this karst system and the only outlet of the Plateau d'Albion.

The 4 sub-systems of the general model exist in this karst system:

- the soil and the epikarstic zone (about few meters),

- the unsaturated zone which is $800 \mathrm{~m}$ thick and has an important hydrodynamic function in the system [12],

- the saturated zone with a thickness upper than $300 \mathrm{~m}$.

The LSBB is situated in the unsaturated zone, about $200 \mathrm{~m}$ above the saturated zone.

\subsection{The LSBB}

The LSBB is hosted in the limestone of the Vaucluse Mounts, in Rustrel. The gallery is almost horizontal under the mountain: its depth varies from 0 to $519 \mathrm{~m}$. The figure 2 shows that the LSBB is also concerned 
A. Perineau et al.: Hydrodynamic organisation of the flows in the unsaturated zone

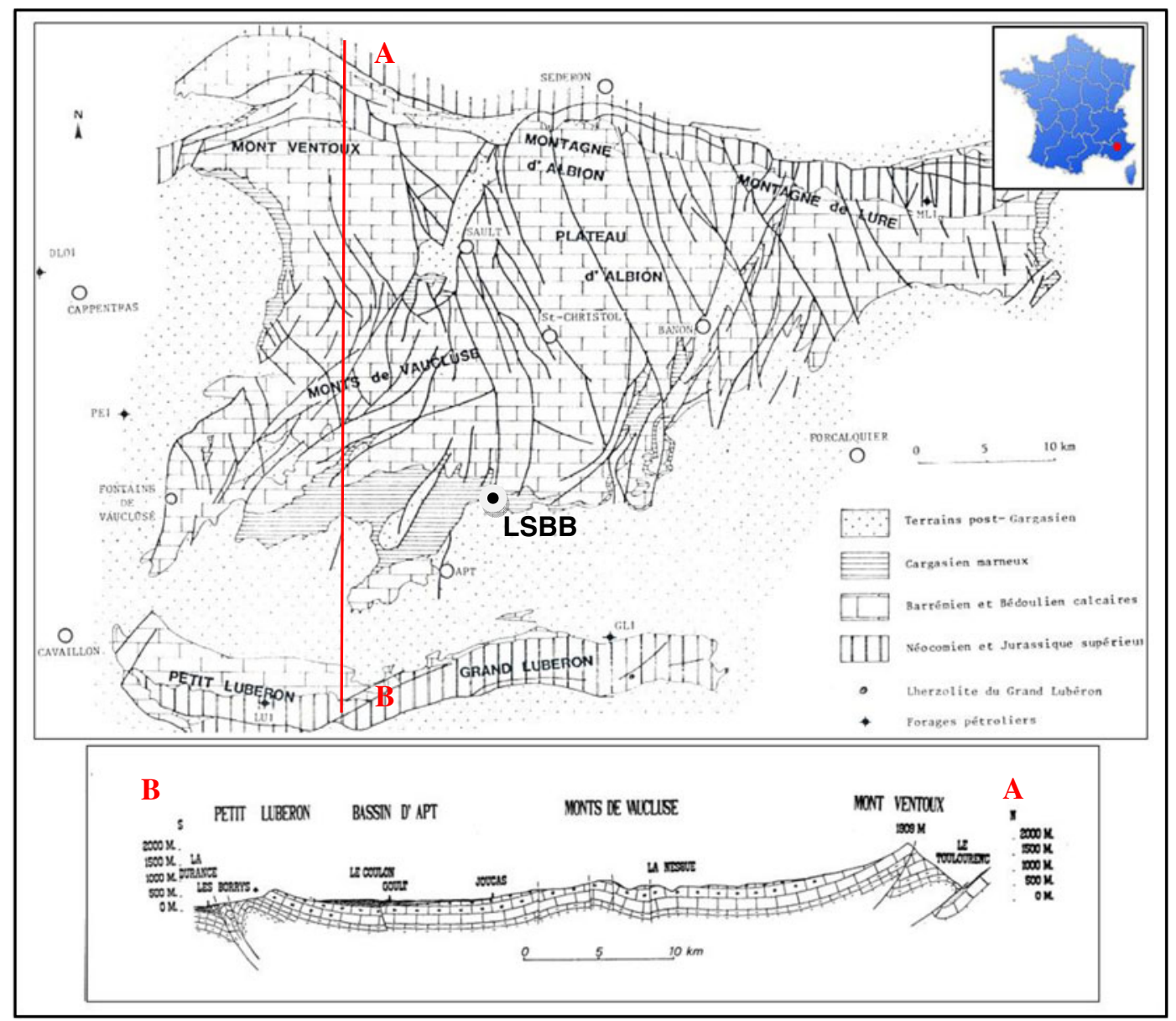

Figure 1. Presentation of the Fontaine de Vaucluse-LSBB karst system (from Puig, 1987 (modified)).

by 2 fault-systems [17]:

- The NE-SW fault-throw, which is observed at the massif scale and also exist in surface at the LSBB scale. The 2 main faults are situated at the East and the West of the area. Between these 2 main faults, many secondary faults of the same system are observed.

- A second fault-throw is identified and oriented E-W to ESE-WNW. The 2 main faults of this system limit a dropped-block.

Deeply, in the gallery (from 0 to $519 \mathrm{~m}$ deep), Thiebaud [17] transcribed the fracturing frequencies (Fig. 3) from geotechnics documents of the gallery digging [18] and showed that the crushed area inside the gallery is in agreement with the surface fracturing.

Therefore, the gallery intersects arbitrarily the fault throws and the fault networks in depth and then the potential areas of flows through the unsaturated zone. Currently, 61 flows have been detected and sampled. As shown in Figure 3 they are located all over the gallery, at different depth (from $30 \mathrm{~m}$ to about $520 \mathrm{~m}$ ) and, the point named GAS excepted, they are named in alphabetical order as and when first sampled. By comparison with classical speleological explorations, it is exceptional to have such an access to the unsaturated zone, i.e. to flows which circulate in a not very karstified network.

For each point, the flow has different behaviors. First of all, for the period of interest (2002-2009), there are 4 points with perennial flows (A, B, C, D) [13] and 57 points with temporary flows. In this instance, a point is considered as a perennial flow point if its flow enables the sampling all over the 


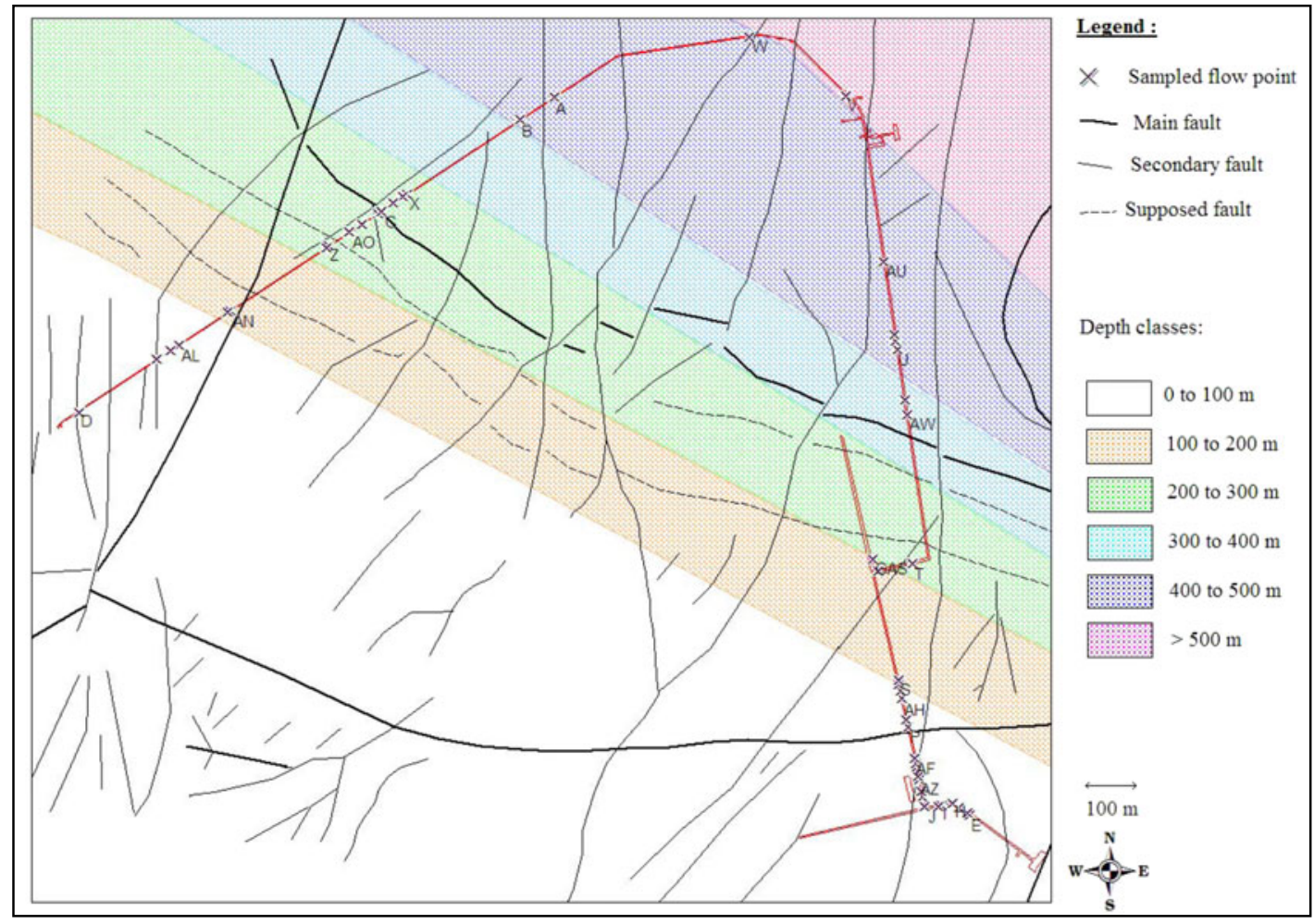

Figure 2. LSBB area, surface fracturing, location of drip water points.

period of the study (2002-2009) on contrary to a temporary flow point, for the same period. The flow rate of each point fluctuates in time with pluviometry and pressure in the massif. The kind of flow varies in space with the depth and the diversity of fracturing throughout the gallery. Therefore the number of flow points enables the study of different kinds of flows in the unsaturated zone. For this study, the depth of 53 georeferenced points is known.

Garry [13] qualified the behavior of the 4 perennial flows and the temporary flow named GAS. Considering the location of flow points with regard to the fracturing, he considered that the points A and $\mathrm{B}$ are located in a fractured zone, the point $\mathrm{C}$ in a crushed zone, the point $\mathrm{D}$ at the base of the epikarstic zone and the point GAS (temporary flow) on a geologic accident (Figure 2).

\subsection{Pluviometry}

From 2000 to 2009, daily rain (Figure 4) was measured at the station of Saint-Saturnin-Lès-Apt which is about $10 \mathrm{~km}$ NE of the LSBB. The Table 1 shows the values of total pluviometry per semester, maximum daily rain per semester and the number of day with values of pluviometry higher than $5 \mathrm{~mm}$ [19] per semester, between 2000 and 2009.

\section{RESULTS}

\subsection{Relations between the pluviometry and the flow points}

The Figure 4 shows the number of running flow points in function of the pluviometry between 2000 and 2009. Many points are noticeable: 
A. Perineau et al.: Hydrodynamic organisation of the flows in the unsaturated zone

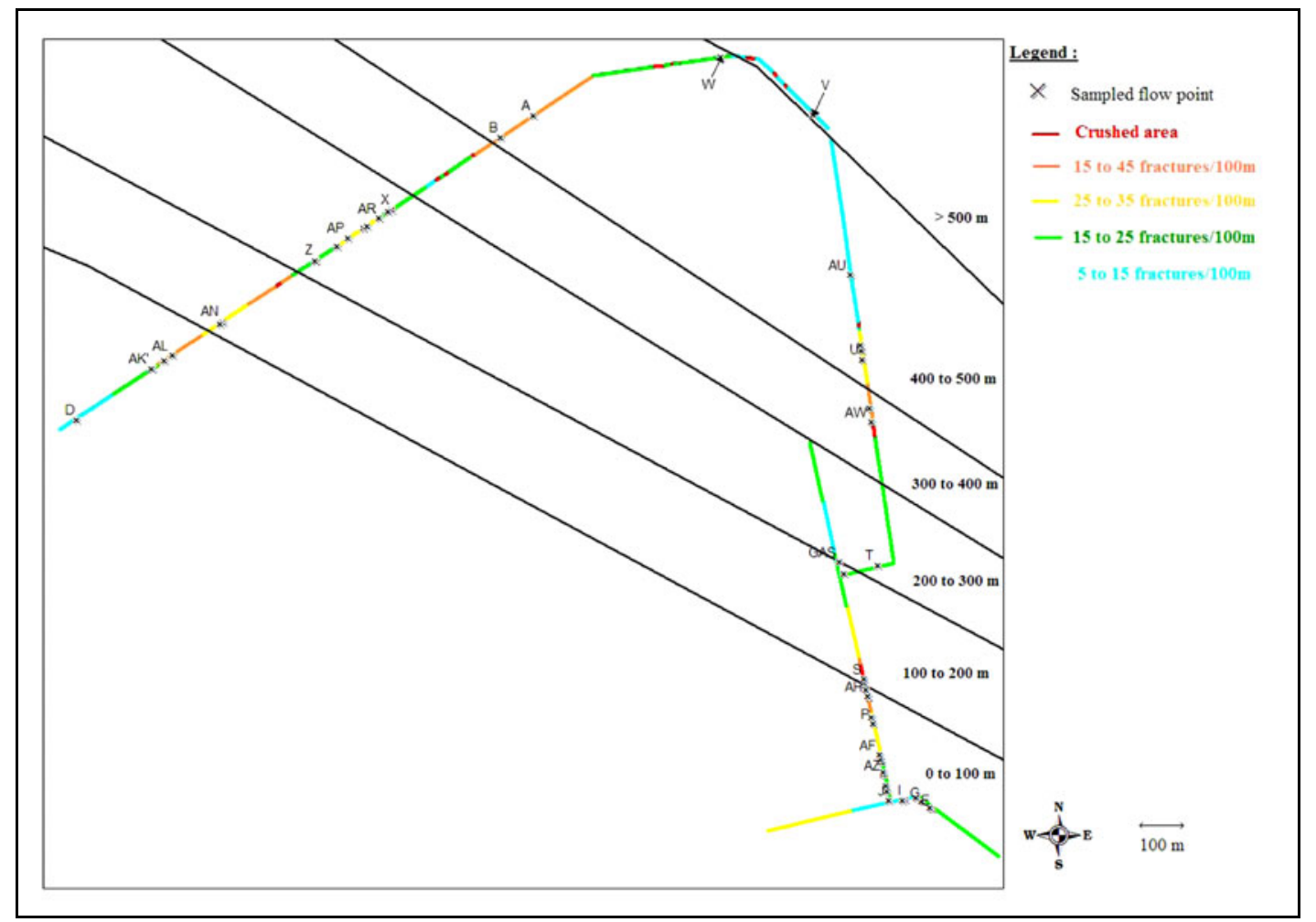

Figure 3. Fracturing frequencies in galleries and drip water points.

Table 1. Total pluviometry (St Saturnin Lès Apt station), maximum daily rain and number of day with pluviometry $>5 \mathrm{~mm}$, per semester, from 2000 to 2009 (CIRAME).

\begin{tabular}{|c|c|c|c|c|c|c|c|c|c|c|c|c|c|c|c|c|c|c|}
\hline & \multicolumn{2}{|c|}{$2000 / 2001$} & \multicolumn{2}{|c|}{ 2001/2002 } & \multicolumn{2}{|c|}{$2002 / 2003$} & \multicolumn{2}{|c|}{$2003 / 2004$} & \multicolumn{2}{|c|}{$2004 / 2005$} & \multicolumn{2}{|c|}{$2005 / 2006$} & \multicolumn{2}{|c|}{$2006 / 2007$} & \multicolumn{2}{|c|}{$2007 / 2008$} & \multicolumn{2}{|c|}{$2008 / 2009$} \\
\hline & \begin{tabular}{|l|} 
Sem.1 \\
\end{tabular} & Sem.2 & Sem.1 & Sem.2 & Sem.1 & $\mid$ Sem.2 & Sem.1 & \begin{tabular}{|l|} 
Sem.2 \\
\end{tabular} & Sem.1 & Sem.2 & Sem.1 & Sem.2 & Sem.1 & Sem.2 & Sem.1 & \begin{tabular}{|l|} 
Sem.2 \\
\end{tabular} & Sem.1 & Sem.2 \\
\hline \begin{tabular}{|c|}
$\begin{array}{c}\text { total pluviometry } \\
(\mathrm{mm})\end{array}$ \\
\end{tabular} & 659,5 & 289,5 & 259,5 & 337,5 & 580 & 140,5 & 545,5 & 188 & 209,5 & 259,5 & 392 & 199,5 & 365 & 237 & 296 & 353 & 658,5 & 221,5 \\
\hline $\begin{array}{c}\begin{array}{c}\text { maximum daily } \\
\text { rain }(\mathbf{m m})\end{array} \\
\end{array}$ & 85,5 & 29 & 26 & 39,5 & 62 & 20 & 90 & 68,5 & 26 & 57,5 & 50,5 & 85 & 57 & 32,5 & 48 & 42 & 79 & 35 \\
\hline \begin{tabular}{|c|}
$\begin{array}{c}\text { Number of day } \\
\text { with pluviometry } \\
>5 \mathrm{~mm}\end{array}$ \\
\end{tabular} & 26 & 17 & 15 & 19 & 28 & 8 & 21 & 8 & 11 & 15 & 14 & 11 & 15 & 12 & 16 & 23 & 26 & 13 \\
\hline
\end{tabular}

- Only the 4 perennial flow points (A, B, C and D) and one temporary flow point (GAS) have run since 2002,

- Between 2002 and 2008, no beginning of flow at new point are recorded,

- Since winter 2008, a lot of new temporary flow points have appeared.

The beginning of the running flow at new temporary points is in relation with the pluviometry. Indeed the calculation of the total annual (by hydrologic cycle) rain from 2002 to 2009 (Figure 4) shows 2 very different periods:

- The first period, from 2002 to winter 2008, is marked by a rain deficit; the minimum value of total annual rain is about $470 \mathrm{~mm}(2004 / 2005)$ whereas the maximum value is about $730 \mathrm{~mm}(2003 / 2004)$.

- The second period, from winter 2008 to today is marked by an excess rain compared with the previous years; the minimum value of total annual rain is about $650 \mathrm{~mm}(2007 / 2008)$ and the maximum value is about $880 \mathrm{~mm}(2008 / 2009)$. 


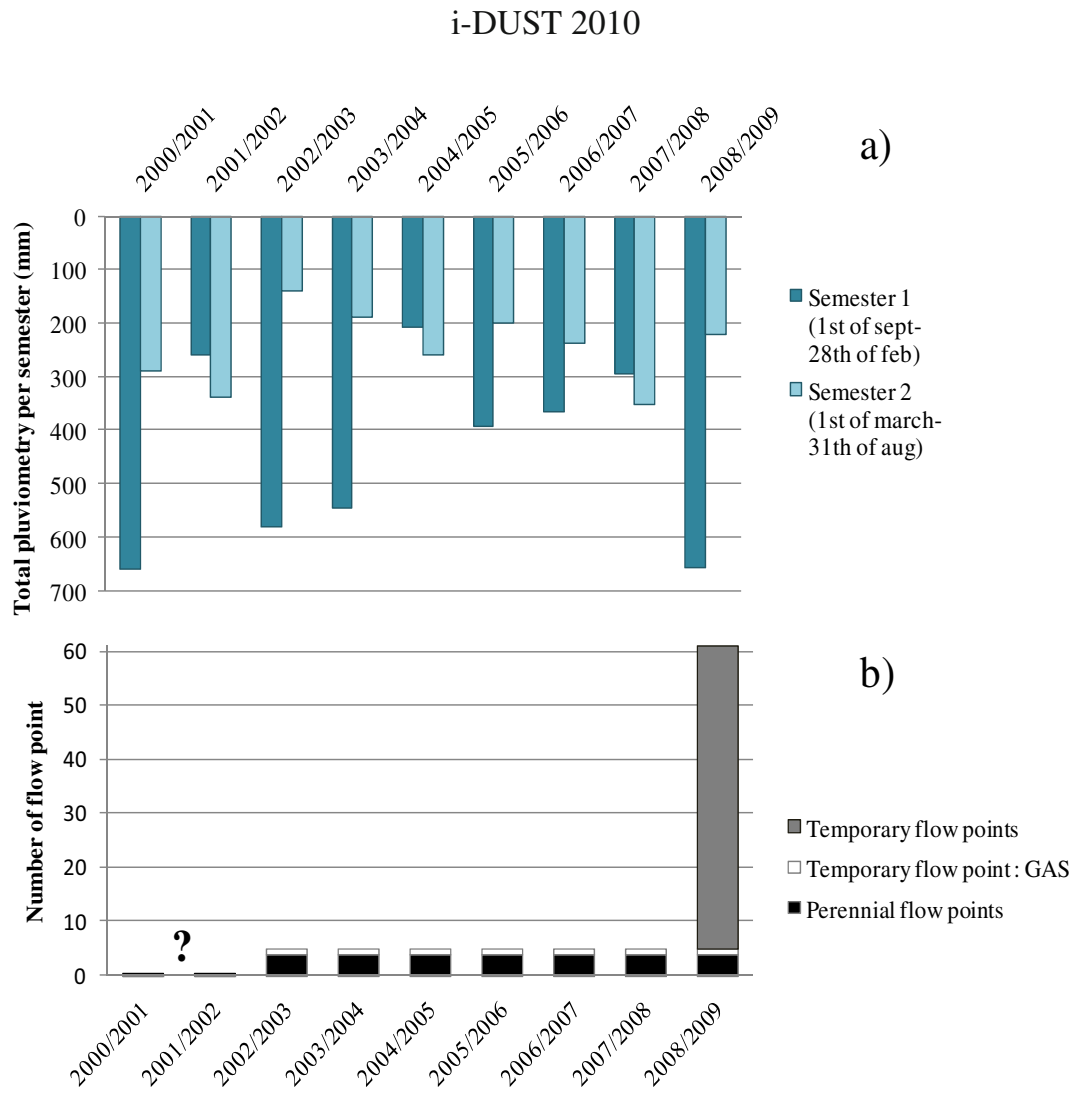

Figure 4. Beginning of flow points in function of pluviometry between 2000 and 2009.

It is important to notice that the increase of the pluviomtery begins in the second semester of the 2007/2008 period: there is a difference between the pluviometry rate during the first semester which corresponds to a dryer period and the last semester which correspond to a wetter period.

Therefore the little number of running flow points between 2002 and winter 2008 matches with the deficiency in rain during this period. The appearance of flow for a lot of new points since winter 2008 matches with the beginning of a wetter period. Then there are 2 periods of characterization of the flows for this present study.

The 4 perennial flow points flow all the year with flow rates from around $0.0021 / \mathrm{min}$ for dry periods to about $1.51 / \mathrm{min}$ for wet periods. The temporary flow points run during important rainy events or periods, with very different flow rates, from around $0.001 \mathrm{l} / \mathrm{min}$ to about $12 \mathrm{l} / \mathrm{min}$. But each temporary flow point has not the same reactivity according to the type and the amount of rain. For example, the flow duration varies from about a day to 7 consecutive months for the period 2008/2009.

During autumn 2008 (semester 1) 53 flow points have run whereas during autumn 2002 (semester 1) only 5 flow points have run, for almost the same quantity of precipitation (resp. 580 and $660 \mathrm{~mm}$ - Table 1). But the quasi-totality of the rainy period in 2008 is concentrated on about 3 months (October, November and December), whereas in 2002, the quasi-totality of the rainy period is about 5-6 months long. Therefore, it seems that an important accumulation of precipitations with low intensity ( $<60 \mathrm{~mm}$ /day) and during a long period (about 5-6 months) as in 2002 is not enough to cause an increase of the number of running flow points in the gallery. Moreover a high quantity of precipitations for 6 months ( $>80 \mathrm{~mm} /$ day) as in 2003 and 2006 but with accumulation of dry periods (total pluviometry per semester between 180 and $390 \mathrm{~mm}$ for the period 2003-2007) doesn't cause any increase of the number of running flow points in the gallery. So as to observe an important increase of the number of 
A. Perineau et al.: Hydrodynamic organisation of the flows in the unsaturated zone

Date
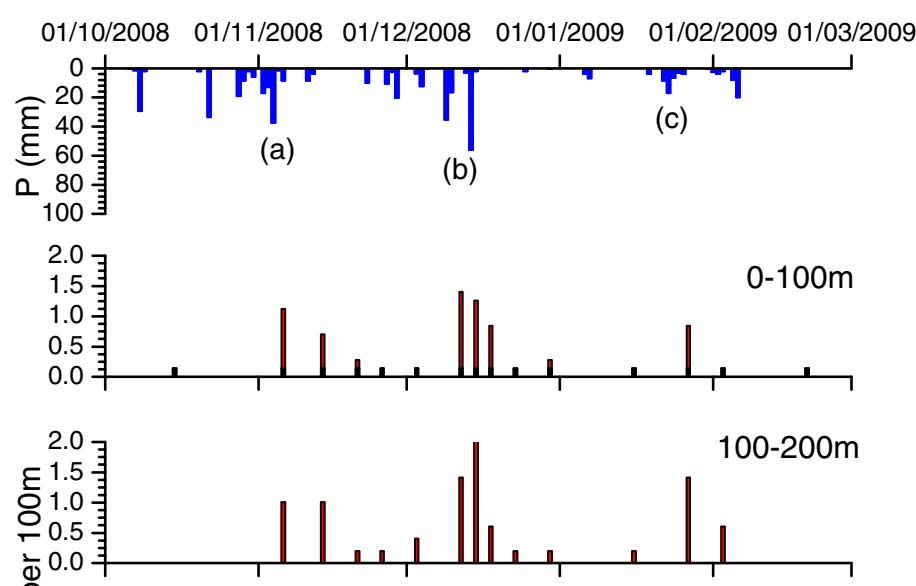

$\Phi$
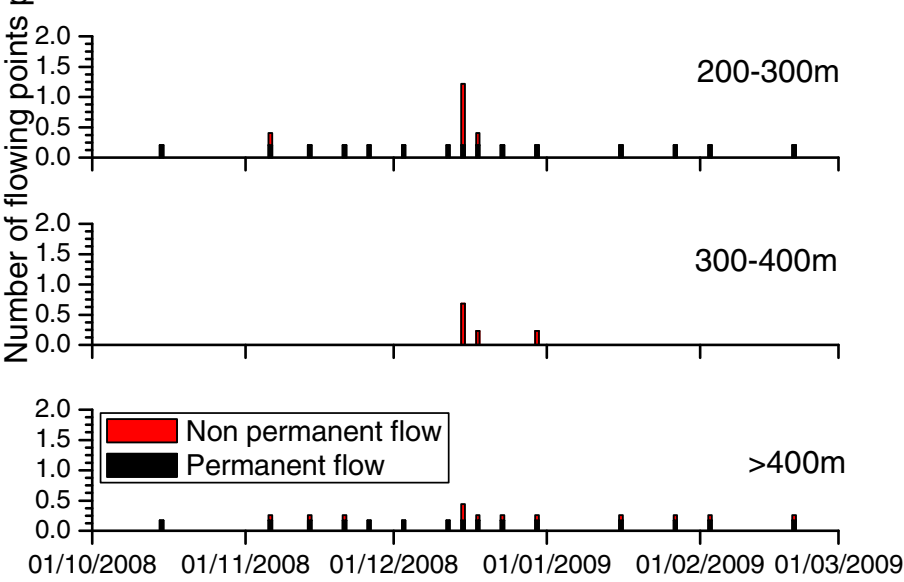

Date

Figure 5. Number of identified flow points per $100 \mathrm{~m}$ for each depth class vs. pluviometry in 2008/2009.

running flow points, as in 2008, it seems to be necessary to combine (i) an important accumulation of precipitations over a preceding period with (ii) a high quantity of precipitations during short periods just before the beginning of the flow. The first accumulation of precipitations could create hydraulic connectivity and stock of water; the following intense rain could induce some pressure increases which cause the beginning of the flow.

Afterwards, only the $2008 / 2009$ period and the 53 flow points that have been recorded and georeferenced for this period will be considered.

The Figure 5 focuses on a rainy period of 2008/2009. It shows, from 01/10/2008 to 01/03/2009, (i) the daily pluviometry and, (ii) the number of flow points reduced to $100 \mathrm{~m}$ of gallery for each depth class. For the flow points, only the discrete measurements (one per week on average) are represented. It is supposed that the flow is continuing between two samplings. This figure permits to identify the presence of an infiltration front in the system.

This infiltration front is well observed for 3 major rainy events:

(a) The first rainy event in November of 2008 ,

(b) The second rainy event in December of 2008,

(c) The last rainy event at the end of January and the beginning of February of 2009. 


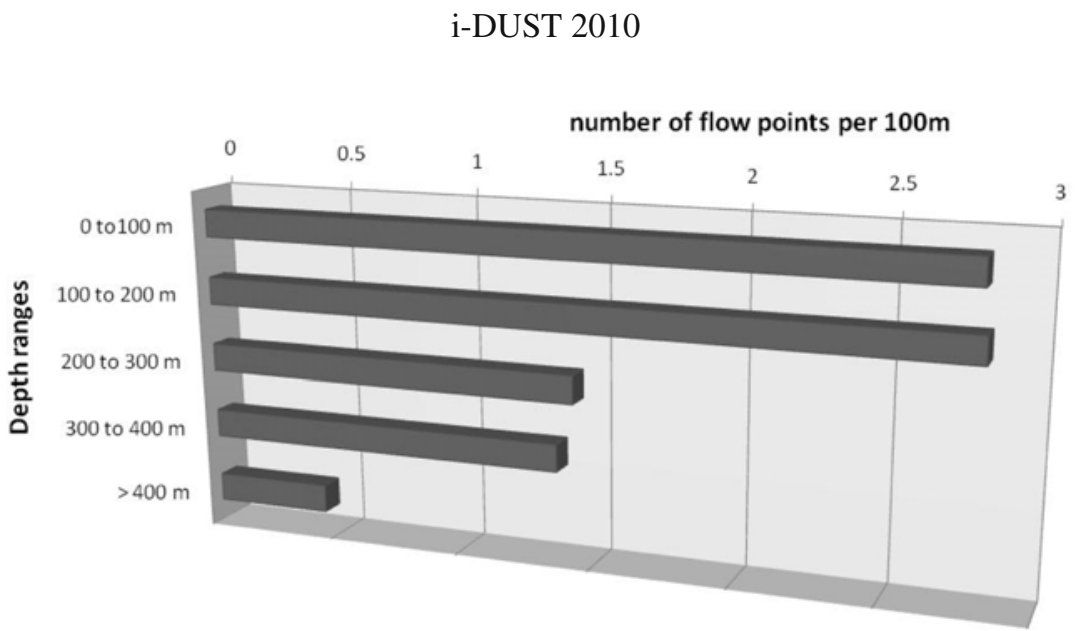

Figure 6. Number of flows points per 100m of gallery in function of depth ranges.

The hydrodynamic of the flow points changes with the depth:

- near the surface (above $200 \mathrm{~m}$ depth) a lot of flow points (between 14 and 20) is observed with low flow rates for short periods, of the order of a few days to 1 month for a few temporary flow points; only 1 perennial flow point (D) belongs these data.

- under $200 \mathrm{~m}$ depth, a few flow points is observed but the flow rates are greater and the impact of the rainy events is more scattered than in surface; for instance, 3 perennial flow points (A, B and C) are under $200 \mathrm{~m}$ depth.

Between 200 and $400 \mathrm{~m}$ depth, only the second event is detected. This event is the most important: more than $150 \mathrm{~mm}$ rained during 1 day. Thus in depth, there are fewer flow points, but this points run over longer periods (up to 2 months) with upper flow rates than near the surface.

These results lead to wonder about the organization of flows with depth. Near the surface, a response to each rainy important episode is well observed. In terms of number of flow points, this response progressively becomes less pronounced with depth whereas in terms of duration of flow, this response progressively increases with depth. These observations reveal a tendency to a decrease of the number of flow points with depth. Moreover the flows tend to become perennial in depth.

\subsection{Relation between the geology and the flow points}

According to geotechnics digging documents [18], the location of the seepages during the digging of the gallery and the location of the flow points (Figure 3) match well. Moreover, this geotechnics documents show that a major part of flow points is situated on geological accidents like fissures, fractures, faults... The flow points situations are also in agreement with seepages of the rock wall observed by geologists during the digging [17] at several faults zone levels.

In depth, the area deeper than $400 \mathrm{~m}$ is a little fractured area, according to a military strategic requirement. In this area, the lack of karstification index and fracturing state could be linked with a number of flow points four times lower than just above (Figure 6).

Therefore there is a clear consistency between the situation of the flow points and the geology. This positive correlation is not surprising but it is one element that confirms representativeness of the sampling.

Concerning the possible relation between the geology and the depth, as it can be seen in the Figure 3, the fracturing density don't seem to follow any particular vertical organization. 
A. Perineau et al.: Hydrodynamic organisation of the flows in the unsaturated zone

Table 2. Number of flow points/Number of flow points per $100 \mathrm{~m}$ vs. fracturing density, for each depth range.

\begin{tabular}{l|c|c|c|c|c}
\hline Range & $0-100 \mathrm{~m}$ & $100-200 \mathrm{~m}$ & $200-300 \mathrm{~m}$ & $300-400 \mathrm{~m}$ & $>400 \mathrm{~m}$ \\
\hline 5 to 15 fractures/100 $\mathrm{m}$ & $\mathbf{4 / 0 . 5 6}$ & $* *$ & $0 / 0.00$ & $0 / 0.00$ & $2 / 0.18^{*}$ \\
15 to 25 fractures/100 $\mathrm{m}$ & $\mathbf{1 1 / 1 . 5 4}$ & $\mathbf{5 / 1 . 0 1}$ & $\mathbf{3 / 0 . 6 1}$ & $0 / 0.00$ & $1 / 0.09^{*}$ \\
25 to 35 fractures/100 $\mathrm{m}$ & $\mathbf{4 / 0 . 5 6}$ & $\mathbf{4 / 0 . 8 1}$ & $\mathbf{3 / 0 . 6 1}$ & $\mathbf{4 / 0 . 9 1}$ & $\mathbf{0 / 0 . 0 0}$ \\
35 to 45 fractures/100 $\mathrm{m}$ & $\mathbf{2 / 0 . 2 8}$ & $\mathbf{5 / 1 . 0 1}$ & $* *$ & $\mathbf{1 / 0 . 2 3}$ & $\mathbf{2 / 0 . 1 8}$ \\
Crushed areas & $0 / 0.00$ & $0 / 0.00$ & $\mathbf{1 / 0 . 2 0}$ & $\mathbf{1 / 0 . 2 3}$ & $\mathbf{0 / 0 . 0 0}(+\mathbf{2}+\mathbf{1}) /$ \\
& & & & & $(+\mathbf{0 . 1 8}+\mathbf{0 . 0 9})^{*}$ \\
Total & $21 / 2.95$ & $14 / 2.82$ & $7 / 1.42$ & $6 / 1.36$ & $5 / 0.44$ \\
\hline
\end{tabular}

\subsection{Relation between the depth and the flow points}

For this study, data have been arbitrarily ranged in classes of $100 \mathrm{~m}$ depth that is sufficient to have at least 5 flow points by class. The number of flow points by depth class has been reduced to a gallery length of $100 \mathrm{~m}$ (Figure 6).

In spite of the particular geology intersected by the gallery under $400 \mathrm{~m}$ depth and the corresponding small number of flow points in this depth class, a decrease with depth of the number of flow points is clearly observed. This number is divided by 2 from $0-200 \mathrm{~m}$ to $200-400 \mathrm{~m}$ depth, and divided again by 2 from $200-400 \mathrm{~m}$ depth to the deepest part.

\subsection{Relation between the geology, the depth and the flow points}

The Table 2 shows the number of flow points in the depth class and the number of flow points per $100 \mathrm{~m}$ of the depth class in function of the fracturing density, for each depth class, during the hydrological cycle 2008/2009.

In this table, there are 4 types of information:

- the existing values that represent the number of flow points and the number of flow points per $100 \mathrm{~m}$ of gallery indicate the presence of flow points at one and the same time in the depth class and in the fracturing class,

- the values are equal to 0 if the considered fracturing density is represented in the considered depth class but any flow point are not observed in the corresponding intersection,

- the cells filled with two asterisks (**) indicate the lack of the considered fracturing density class in the considered depth class,

- the values marked with one asterisk (*) in the " $>400 \mathrm{~m}$ " depth class are particular values; indeed the value of 0.18 in the " 5 to 15 fractures per $100 \mathrm{~m}$ " fracturing class and the value of 0.09 in the " 15 to 25 fractures per $100 \mathrm{~m}$ " fracturing class represent 3 flow points that are situated in little crushed areas [18]. Due to their very small extension, these local crushed areas are not taken into account in the statistical calculations of the number of fractures per $100 \mathrm{~m}$ (each little area is simply considered as one fracture). That is why these two values (0.18 and 0.09$)$ have been finally included in the corresponding cell for the "crushed area" class.

Higher values have been highlighted with bold in order to underline the organization of the flows with depth. Whereas any vertical organization of the fracturing density has not been demonstrated yet, it seems that more the depth increases, more the flow points are located in areas with higher fracturing density.

\section{DISCUSSION}

These results are useful to specify the conceptual model of the hydrodynamic functioning of the unsaturated zone. At the surface, the water enters in the karst system by any fracture and whatever 
i-DUST 2010

the fracturing density. The progression of the water toward the saturated zone needs some hydraulic connectivity between the surface and the saturated zone which involves physical links between discontinuities. As the water is going deep into the karst system, the flow tends to converge in areas with high fracturing density, i.e. where the connectivity between discontinuities is higher. With the increasing depth, these areas with high fracturing tend to become areas with preferential path flows. The number of flow points decreases with the increasing depth (Table 2), according to an organization of the flows. Moreover the measured flow rates (not presented here) show that the mean discharge of each flow point increases with the increasing depth.

However, the data considered in this study come from sampling that are discrete in space and time. In space, 53 flow points are georeferenced over a gallery that is near $3.8 \mathrm{~km}$ long and from 30 to $519 \mathrm{~m}$ deep. In time, all the data have been recorded (i) only for one hydrological cycle (2008/2009) and (ii) with one sampling by week on average. The question of the representativeness of these data to qualify the hydrodynamic functioning of the unsaturated zone must be asked.

Can the hydrologic cycle 2008/2009 be representative? As it is shown in the Figure 4, the studied hydrologic cycle is a wet cycle after 7 dry years (the last 4 cycles are particularly dry, with less than $50 \%$ of mean annual rainfall). This study is carry out in a context of particularly low-level stocks and low hydraulic connectivity. Therefore mistakes which could be caused by a non-homogenous distribution of those are minimized. Nevertheless these particularities could explain the short duration of some temporary flows, which doesn't change anyway the underlined organization of the flows. Data acquisition during other hydrological cycles should enable to specify the conclusion.

Can the discrete sampling be representative of the continuum of the unsaturated zone with depth? The use of depth classes that include at least 5 flow points (near $10 \%$ of the total) evenly distributed in the gallery by class was a mean to ensure the presented interpretation. In the same way, any precise use of the variation of the flow rates with the time has not been done; just some qualitative comments about the variation of the number of running flow points with the time have permitted to underline some characteristics of the organization of the flows with the pluviometry or the depth. Therefore, even if they are discrete, the considered data seem to be sufficient to validate the qualitative organization of the flows presented here.

In this study, rainfall data of Saint-Saturnin-Lès-Apt pluviometric station were used. This station is situated at about $8 \mathrm{~km}$ of the LSBB. The characteristics (time, intensity, quantity) of the rainfall on the studied site could be a little different. However only the most important and non local rainy episodes have been considered here. So it seems possible to consider this pluviometric station enough representative for this study.

Finally, the considered data seem to be sufficient to ensure the presented interpretation. Nevertheless, other sampling for future hydrological cycles, new flow points and continuous data acquisition will be interesting to validate those. Even if the presented methods remain generic and even if the presented organization of the flows is probably common to a lot of karst systems, other measurements will be necessary to upscale first to the whole Fontaine-de-Vaucluse karst system and secondly to a generic conceptual model.

\section{CONCLUSIONS AND PERSPECTIVES}

First, the rainfall characteristics which are in accordance with some flows in the unsaturated zone have been shaped. It seems to be necessary to combine (i) an important accumulation of precipitations over a preceding period with (ii) a high quantity of precipitations during short periods just before the beginning of the flow. The first accumulation of precipitations could create hydraulic connectivity and stock of water; the following intense rain could induce some pressure increases which cause the beginning of the flow.

Particularly, this study clearly underlines an organization of the flows with the depth in the unsaturated zone of the karst system, as it was already suggested in literature [1]. Whereas this 
A. Perineau et al.: Hydrodynamic organisation of the flows in the unsaturated zone

organization is generally proposed upon theory and sometimes with localized observations, it is here demonstrated owing to in-situ observations.

More the depth increases and more flows converge to areas with high fracturing density. Indeed, in areas with high fracturing density, the high number of discontinuities ensures the continuity of flows, thus creating preferential flowpaths, more and more organized into a hierarchy. The measurements also underline a tendency to perennial characteristics of the flows with increasing depth. The distribution of flow points in space, its clustering and the scatter of flow rates with increasing depth show this flow organization in the unsaturated zone. Indeed (i) the variability of the number of flows decreases with increasing depth and (ii) when a temporary flow point begins to run, the duration of the flow tend to increase with increasing depth.

Finally, the continuing data acquisition would enable the generalization of these results and maybe the development of a conceptual model for the hydrodynamic functioning of the unsaturated zone of the karst systems. The sampling of other flow points in the same site and even in other sites would be obviously interesting. Considering the lack of access to the unsaturated zone of the karst systems, a better understanding of the relation between on the one hand geology and hydrodynamic and on the other hand geology and depth could be another way to generalize these model to a lot of karst systems where the geology is known.

\section{References}

[1] Ford, D. and Williams P. (2007), Karst Hydrogeology and Geomorphology; John Wiley \& Sons, $562 \mathrm{p}$.

[2] Bakalowicz, M. and Dörfliger N. (2005), Les ressources en eau du karst: un enjeu pour le bassin méditerranéen. Géosciences, la Revue du BRGM. 2: p. 26-31.

[3] Blavoux B. and Mudry J. (1993), Use of the physico-chemical variations of karst waters to understand how an aquifer works: example from the Fontaine de Vaucluse system (Southeastern France). Hydrogeological Processes in Karst Terranes (Proceedings of the Antalya Symposium, october 1990), I.A.H.S. Publ. N²07, p. 327-333.

[4] Falcone R.F., Falgiania A., Parisseb B., Petittac M., Spizzicod M., Tallin M., (2008), Chemical and isotopic ( $\delta 18 \mathrm{O} \%, \delta 2 \mathrm{H} \%$ o, $\delta 13 \mathrm{C} \% 0,222 \mathrm{Rn})$ multi-tracing for groundwater conceptual model of carbonate aquifer (Gran Sasso INFN underground laboratory-central Italy). Journal of Hydrology, Volume 357, Issues 3-4, 15 August 2008, Pages 368-38.

[5] Perrin J., Jeannin P.-Y., Zwahlen F. (2003), Epikarst storage in a karst aquifer: a conceptual model based on isotopic data. Milandre test site, Switzerland. Journal of Hydrology, 279(1-4): 106-124.

[6] Bakalowicz M. (2005), Karst groundwater: a challenge for new resources. Hydrogeology Journal Volume: 13 Issue: 1 Pages: 148-160.

[7] Mangin, A. (1975). Contribution à l'étude hydrodynamique des aquifères karstiques. PhD Thesis, Université de Dijon, Dijon, 260 pp.

[8] Lastennet R., Puig J.M., Emblanch C. et Blavoux B. (1995), Influence de la zone non saturée sur le fonctionnement des systèmes karstiques. Mise en évidence dans les sources du Nord-Vaucluse. Hydrogéologie, n 4, 1995, p. 57-66.

[9] Emblanch C., Garry B., Blondel T., Marc V., Andreo B. (2006), Karst aquifers: a high diversity but also a same identity. IIIème Symposium International Sur Le Karst, Groundwater in the Mediterranean countries Malaga (SPAIN), 24-28 April 2006, p49-57.

[10] White W. B (2002) Karst hydrology: recent developments and open questions. Engineering Geology, Volume 65, Issues 2-3, August 2002, Pages 85-105, Elsevier, doi:10.1016/S00137952(01)00116-8.

[11] White W. B , (2006) Conceptual models for carbonate aquifers. Ground Water, Volume 7 Issue 3, Pages 15-21. 
[12] Emblanch, C., Zuppi, G.M., Mudry, J., Blavoux, B. \& Batiot, C. (2003). Carbon 13 of TDIC to quantify the role of the unsaturated zone: the example of the Vaucluse karst systems (Southeastern France). Journal of Hydrology, 279(1-4): 262-274.

[13] Garry, B., Blondel, T., Emblanch, C., Sudre, C., Bilgot, S., Cavaillou, A., Boyer, D. \& Auguste, M. (2008). Contribution of artificial galleries to knowledge of karstic system behaviour in addition to natural cavern data. International Journal of Speleology, 37(1): 75-82.

[14] Cognard-Plancq, A.-L., Gevaudan, C. \& Emblanch, C. (2006). Historical monthly rainfall-runoff database on Fontaine de Vaucluse karst system : review and lessons, Karst, cambio climatico y aguas submediterraneas, Malaga, pp. 465-475.

[15] Masse, J.P. (1968). L'Urgonien de Sault (Vaucluse). Bulletin de la Société Géologique de France, 9(4): 495-596.

[16] Masse, J.P. (1972). Structures cryptalgaires libres dans un complexe carbonaté de plate-forme: les calcaires urgoniens (Barrémien) de Provence (Sud-Est de la France). 24th International Geological Congress, Montreal, 7: 572-585.

[17] Thiébaud, E. (2003). Etude structurale et hydrogéologique du site du Laboratoire Souterrain à Bas Bruit de Rustrel, Rapport de Master, Université de Franche-Comte, Besançon, 50 pp.

[18] CEBTP (1968), Mont Ventoux, Rustrel, PCT 1, Etude géotechnique. Dossier SF 67/223.6.039

[19] Celle-Jeanton, H. (2000). Caractérisation des précipitations sur le pourtour de la Méditerranée occidentale - Approche isotopique et chimique. PhD Thesis, Université d'Avignon et des Pays du Vaucluse, Avignon, $222 \mathrm{pp}$. 